\title{
Medical Marijuana and the Treatment of Post Traumatic Stress Disorder: A Survey of Michigan Psychiatrists' Opinions
}

\author{
Jason Custodia, DO', Jed Magen, DO, MS², William D. Corser, PhD, RN ${ }^{3}$ \\ 1 Veteran's Administration Los Angeles Healthcare System Los Angeles, CA, 2 Department of Psychiatry, MSU College of Osteopathic Medicine, East \\ Lansing, MI; Statewide Campus System, MSU College of Osteopathic Medicine, East Lansing, MI, ${ }^{3}$ Statewide Campus System, MSU College of \\ Osteopathic Medicine, East Lansing, MI \\ Keywords: medical marijuana, post-traumatic stress disorder, symptom relief \\ https://doi.org/10.51894/001c.5117
}

\section{Spartan Medical Research Journal}

Vol. 1, Issue 2, 2017

\begin{abstract}
CONTEXT
Although recent studies have indicated a potential mechanism of action through which medical marijuana (MM) and its derivatives may treat Posttraumatic Stress Disorder (PTSD) symptoms, definitive evidence is still lacking. Few studies concerning physician attitudes regarding MM and/or marijuana-derived medications for PTSD are found in the psychiatric literature.
\end{abstract}

\section{METHODS}

A non-probability convenience sample of psychiatric physicians in Michigan was surveyed during 2016. The 12-item survey questionnaire asked respondents a series of questions about their personal characteristics, prior experiences of treating PTSD and opinions concerning the use/potential use of MM for treatment of PTSD.

\begin{abstract}
RESULTS
A total of 83 psychiatrists (11.7\% of total invited) responded to the survey. Several statistically significant correlations between respondent characteristics and other key measures (e.g., Age Category, Gender, Years of Psychiatric Practice, Psychiatric Practice Role (i.e., resident vs. attending), Number of Psychiatric Subspecialties, and Number of PTSD Patients Diagnosed and/or Treated to date) were found. A composite summary score was also formulated from questions related to opinion regarding the use of MM for PTSD and categorized into three comparison groups. The final stepwise multinomial logistic model demonstrated three statistically significant factors influencing what response category respondents fell into regarding MM use for PTSD: a) how often respondents had been exposed to recommendations concerning the use of MM for PTSD ( $p<0.001)$, b) Age Category $(p=0.001)$ and how frequently respondents had recommended MM for treatment of PTSD $(p<0.001)$.
\end{abstract}

\section{CONCLUSIONS}

The results from this smaller sample indicate that the majority of psychiatrist respondents did not support MM for the treatment of PTSD. Judging from these results, Michigan psychiatrists may be extremely conservative regard the prospective use of MM for PTSD. Few sample respondents indicated that they had been exposed to professional literature detailing MM and derivatives as a treatment for PTSD. Most respondents also indicated that they were Unsure/There is Not Enough Research concerning the scientific evidence for the use of MM for PTSD. Based on these findings from a smaller sample, the use of MM and its derivatives for treatment of PTSD may not currently be supported by the majority of Michigan psychiatrists.

\section{INTRODUCTION}

Post-traumatic Stress Disorder (PTSD) is a psychiatric condition resulting from having experienced or witnessed a traumatic event, with a characteristic constellation of symptoms including event re-experiencing, avoidance of event reminders, and hyper-arousal. ${ }^{1}$ Although the great majority of people who experience a traumatic event never develop PTSD, some may develop long-lasting symptoms which can greatly affect their daily functioning and overall quality of life.

According to the U.S. National Institute of Mental 
Health's most recent statistics, PTSD has a lifetime prevalence of $6.8 \%$, with a 12 -month prevalence of $3.5 \%$. Of those cases, over a third are classified as severe. ${ }^{2}$ Although PTSD is among the most debilitating and prevalent of psychiatric conditions, it remains among the most recalcitrant conditions to treat with highly variable prognoses. ${ }^{3}$ Indeed, some patients suffer from reemergence of symptoms in spite of prolonged treatment. ${ }^{3}$

Clinicians' typical difficulty in ameliorating the symptoms of PTSD has driven a search for potential therapeutic agents that may provide relief. ${ }^{3}$ For many patients afflicted with PTSD, the only agent they feel can effectively palliate their symptoms may be medical marijuana (MM). ${ }^{4}$ Although marijuana has been listed as a Schedule I controlled substance since the inception of the Controlled Substances Act of $1970,{ }^{5}$ there has been a growing movement to approve its use as a specific therapeutic agent for PTSD. In seven states and the District of Columbia, PTSD is now an approved condition for the prescribed use of MM. ${ }^{6}$

In 2014, the State of Michigan legislature approved the therapeutic use of MM for PTSD after a panel of non-physician experts heard patients' testimony. ${ }^{7}$ However, these MM use policy changes came with little input from physicians, and virtually none from psychiatrists, those clinicians most likely to treat PTSD. Currently, national psychiatric PTSD treatment guidelines do not universally advocate including the therapeutic use of marijuana or any marijuana-derived medications. ${ }^{3,8}$ In fact, the most recent practice 2009 guideline update from the American Psychiatric Association makes no mention of marijuana as a possible treatment option for PTSD. 8

Due to MM's conflicting legal status (i.e., being legal at the state level but illegal at the federal level), very few, if any, physicians now appear to prescribe marijuana in any form to patients. ${ }^{4}$ Although studies concerning the effects of marijuana and its derivatives have steadily increased during the past decade, there are still only a handful of published studies concerning the effect of MM on PTSD symptoms. ${ }^{8}$

\section{PTSD AND MARIJUANA USE}

There has long been an anecdotal association between the use of marijuana and PTSD symptoms. ${ }^{4}$ Most studies to date have focused on the well-known negative consequences of cannabis use, including an increased risk for several other substance use disorders. ${ }^{4}$ However, other groups have sought to specifically examine the relationship between PTSD symptoms and MM use.

For example, a study in 2011 by Cougle et. al., determined that having a diagnosis of PTSD significantly increased the odds of a lifetime patient history of cannabis use, with $50 \%$ of sample subjects stating that their PTSD symptoms occurred prior to, or around, the same time as their first cannabis use. ${ }^{9}$ A similar follow-on study demonstrated that cannabis users with higher PTSD scores were significantly more likely to use cannabis to improve their sleep and coping than subjects with lower PTSD scores. ${ }^{10}$ The results from these initial studies have suggested that MM may exert some neurobiological effect resulting in perceived relief of PTSD symptoms.

\section{NEUROBIOLOGICAL BASIS FOR THE USE OF MARIJUANA} IN PTSD

Within the past five years, more critical reviews of the medical literature regarding the use of marijuana for PTSD symptoms have been published. These reviews have cited many of the findings already described in this paper, but have also provided some notable new insights. Two separate reviews detailed marijuana's possible mechanism of action through the effects of delta-9-tetrhydrocannabinol (THC), the main psychoactive cannabinoid in marijuana, on endogenous cannabinoid receptors of the brain's endocannabinoid system (ECS). ${ }^{11,12}$ The ECS appears to be involved in memory formation, fear, and emotion or executive functioning, areas of the brain likely active during memory formation/extinction in PTSD. ${ }^{11,12}$

Other studies have focused on the effects of marijuanaderived medications on the ECS, including the FDA-approved medication Dronabinol 13 (i.e., indicated for appetite stimulation in cancer patients and anorexia), the synthetic cannabinoid Nabilone ${ }^{14}$ (i.e., primarily used as an antiemetic for cancer), and the endogenous cannabinoid neurotransmitter Anandamide (for anxiety/depression). ${ }^{15}$ Some research has focused on imaging studies using positron emission tomography (PET) to examine the ECS, showing an increase in the concentration of cannabinoid receptor availability in subjects with PTSD versus healthy controls. ${ }^{16}$

However, there is still a dearth of information about psychiatrists' opinions on this topic. Only one survey project was found by the authors during the past 20 years that attempted to gauge physicians' opinions on the use of MM for any indication. ${ }^{17}$ The results from this project indicated that physicians were, in general, less supportive than the general public regarding the use of MM. ${ }^{17}$

In summary, research has indicated that the ECS appears to be a viable therapeutic target to treat PTSD, and that cannabinoids (both synthetic and endogenous) may be potential therapeutic agents. However, many of these studies used smaller samples and have not been replicated. Furthermore, it remains unknown whether these results have been routinely disseminated to practicing psychiatrists.

In light of the increasing number of states legally approving MM for PTSD, it is imperative to examine the opinions of behavioral health professionals who treat PTSD about this newer treatment modality. Since psychiatrists most frequently treat PTSD patients, their expertise is extremely important in helping shape the discourse concerning this potential PTSD treatment.

\section{PROJECT PURPOSE}

This exploratory pilot study was conducted to investigate the perspectives of psychiatrists on the evolving topic of MM use for treatment of PTSD. The authors conducted a survey of attending and resident psychiatrists in Michigan to ask respondents a number of questions related to the potential use of MM and/or its derivatives for the treatment of PTSD. A secondary goal of this study was to clarify psychiatrists' current opinions concerning the use of MM versus marijuana-derived medications for the treatment of PTSD 
symptoms.

Before the study, the authors had generally hypothesized that younger (i.e., resident) psychiatrists would be more receptive to prescribing MM for PTSD. In addition, the authors had speculated that those respondents more familiar with guarded recommendations from groups (e.g., American Academy of Neurology, ${ }^{18}$ Federation of State Medical Boards ${ }^{19}$ ) for the use of MM to palliate PTSD symptoms would prove more supportive.

\section{METHODS}

A cross sectional email-based survey was distributed to a total of 723 licensed psychiatrists in the state of Michigan between February 11, 2016 and March 11, 2016 using the Survey Monkey internet-based survey program. ${ }^{20}$ The survey developed by the first two authors asked respondents a series of 12 questions regarding their professional opinions about MM and its derivatives as choices for the treatment of PTSD symptoms. Most opinion questions used a Likerttype scale, including No Response/Unsure response option. An additional open-ended comment item was also added at the end of the survey to further gauge psychiatrists' opinions on the study topic (see Figure 1).

\section{STUDY POPULATION}

Subjects were drawn from an email database of psychiatrists currently practicing in the state of Michigan. The email database had been obtained from the state branch of the American Psychiatric Association, with study approval obtained through the Michigan State University institutional review board.

\section{DATA ANALYSES}

All data analyses were conducted using S.P.S.S. Version $22 .^{21}$ A series of descriptive statistics were first generated with cross-tabulations completed to examine for statistically significant bivariate correlations across major study measures to inform the conservative selection of later multivariate modeling procedure model terms. Key correlations between respondent characteristics (i.e., Age Category, Gender, Years of Psychiatric Practice, Psychiatric Practice Role (i.e., resident vs. attending psychiatrist), Number of Psychiatric Subspecialties, and Number of PTSD Patients Diagnosed and/or Treated to Date) were initially examined.

Finally, a forward stepwise Main Effects multinomial logistic regression (MLR) model comprised of potentially-significant model terms was conducted. Such a modeling procedure was more appropriate for this non-normally distributed sample to predict the probability of use of MM for PTSD category membership based on major respondent characteristics. $^{22}$ In this MLR model, each model term was entered individually (i.e., stepwise) to gauge their significance for the three composite score categories (i.e., Generally Against Use of MM for PTSD, Neither Against of Supportive of Use of MM for PTSD and Generally Supportive of Use of MM of PTSD), with those variables with non-significant test statistics (i.e., greater than $p$ value of 0.100 ) removed from the final predictive model.

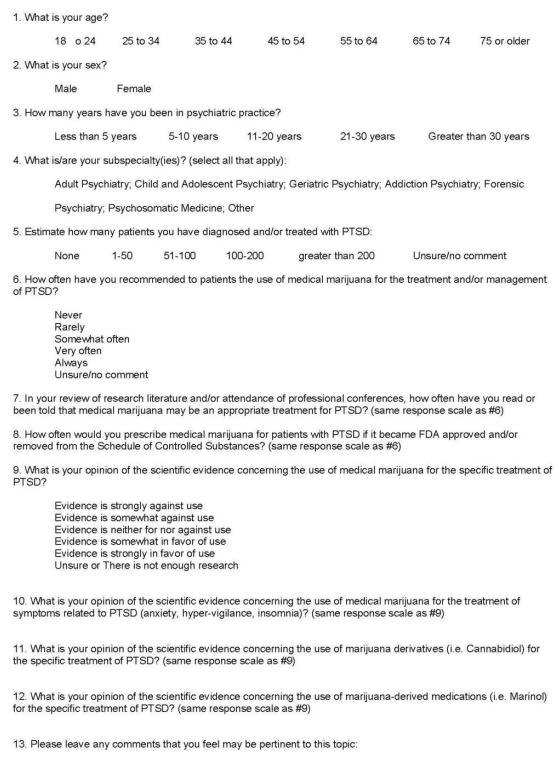

Figure 1: Survey Items of Psychiatrists' Opinions on Medical Marijuana for Post-Traumatic Stress Disorder

\section{RESULTS}

Of the 723 email surveys sent, 16 (2.2\%) were not successfully delivered due to invalid email addresses. Of the 707 remaining surveys sent to active email accounts, 83 (11.7\% of total invited) subjects responded to the survey. A total of 34 (41\%) respondents reported being younger than 35 years of age, with the seven age categories of respondents quite diverse. A total of 44 (53.0\%) respondents were males (See Table 1).

A total of 42 respondents (50.6\%) reported having practiced in psychiatry for less than five years at time of survey. The average number of psychiatric subspecialties reportedly held by respondents was 1.05 (SD 0.825). Forty-eight (57.8\%) sample respondents reported having diagnosed or treated a broad range of between 1 and 100 PTSD patients at time of survey, with 26 (31.3\%) additional respondents indicating that they had treated more than 100 PTSD patients (See Table 1).

Notably, only one respondent (1.2\%) indicated that they Sometimes recommended the use of MM for PTSD, with the great majority of the remaining sample answering Never (90.4\%). Only 11 (13.3\%) of total respondents indicated that they had Sometimes or Often been exposed to the notion of MM being an appropriate PTSD treatment in the professional literature or at conferences.

Thirty-one respondents (37.4\%) stated they would Never prescribe MM, even if it became FDA approved and/or removed from the federal Schedule of Controlled Substances. Twenty-five other respondents (30\%) said they would Rarely prescribe MM for PTSD, with 17 of remaining respondents (20.5\%) surveying that they were Unsure/No Comment. In the survey items related to respondents' opinions on the ac- 


\begin{tabular}{|c|c|c|}
\hline & $\mathrm{n}$ & $\%$ of category \\
\hline \multicolumn{3}{|l|}{ 1. Age Category* } \\
\hline 18 to 34 Years Old & 34 & 41.5 \\
\hline 35 to 54 Years Old & 29 & 35.4 \\
\hline 55 Years and Older & 19 & 22.9 \\
\hline \multicolumn{3}{|l|}{ 2. Gender* } \\
\hline Male & 44 & 53 \\
\hline Female & 38 & 45.8 \\
\hline \multicolumn{3}{|c|}{ 3. Years of Psychiatric Practice * } \\
\hline Less than Five Years & 42 & 50.6 \\
\hline Five to 20 Years & 22 & 26.5 \\
\hline 21 Years or More & 18 & 21.7 \\
\hline \multicolumn{3}{|c|}{$\begin{array}{l}\text { 4. Number of Patients Diagnosed/Treated } \\
\text { for PTSD To Date }\end{array}$} \\
\hline None & 1 & 1.2 \\
\hline Between 1 and 100 Patients & 48 & 57.8 \\
\hline Greater than 100 Patients & 26 & 31.3 \\
\hline Missing & 8 & 9.6 \\
\hline
\end{tabular}

* Data from One Respondent Missing

tual scientific evidence of MM for the treatment of PTSD (Questions 9-12 in Figure 1), a majority of the respondents $(\mathrm{n}=44)$ selected the answer Unsure/There is Not Enough Research.

\section{KEY (SIGNIFICANT AND NON-SIGNIFICANT) BIVARIATE CORRELATIONS INCLUDED:}

1. Age Category with a) Gender ( $p=0.030$, with women respondents tending to be younger), and b) Category of Number of PTSD Patients Diagnosed/treated to date $(p<0.001$, with older respondents having treated more PTSD patients);

2. Years of Psychiatric Practice with likelihood category of having recommended $\mathrm{MM}$ to patients more frequently in the past $(p=<0.001)$, with more experienced respondents more likely to recommend MM for PTSD); and

3. More frequent exposures to recommendations concerning use of MM and composite MM use belief score category ( $p=0.001$, with more frequently-exposed respondents more likely to prescribe).

The survey included three different related questions related to respondents' opinions regarding use of MM to treat PTSD which were conservatively categorized into three overall groups: 1. Neither Against or Supportive of MM use for PTSD, $(\mathrm{n}=11,13.3 \%) 2$. Generally Against MM use for PTSD, $(\mathrm{n}=19,22.9 \%)$ and 3. Generally Supportive of $M M$ use for PTSD $(\mathrm{n}=9,10.8 \%)$. It should be acknowledged that 44 respondents (53.0\%) opted to not answer at least one of these three survey items. This overall opinion categorical measure was treated as a de facto outcome measure for most subsequent analyses.
In the final MLR stepwise model for outcome, the following model terms remained statistically significant after controlling for other non-significant model terms: a) How Often Respondent had been Exposed to Recommendations concerning use of MM for PTSD patients $(p<0.001)$, b) Age Category ( $\mathrm{p}=0.001)$, and $\mathrm{c}$ ) How often Respondent had Previously Prescribed MM for PTSD ( $\mathrm{p}<0.001)$ (see Figures 2, 3, and 4 for general depiction of key results). The goodness of fit and other model fitting information from the final MLM model were each quite adequate, although the number of respondents with entirely complete survey data that could be included into this stepwise model was especially low ( $\mathrm{n}=$ 27). Still, the authors were able to identify these statistically significant predictors of respondents' opinions regarding MM use for PTSD in spite of their limited sample size.

\section{LIMITATIONS}

This study did have several constraints related to the inherent limitations of smaller cross-sectional survey studies. The results may have also been skewed by other unmeasured factors, including a self-selected group of psychiatrists actually responding to the survey. For instance, respondents in this sample were predominantly young and less experienced, with approximately $40 \%$ in the $25-34$ years age group category and over half of the respondents in psychiatric practice less than five years.

Based on fairly loose national estimates, it is certainly possible that these respondents comprised a somewhat non-representative (i.e., younger and less-experienced than average) group of Michigan psychiatrists. ${ }^{23}$ As for the survey tool itself, the questionnaire had not been psychometrically tested before the study, having only been previously examined by several psychiatric experts for overall validity. 
During these initial survey reviews, the clarity of some of the questions wording and use of terms and response options had been edited.

\section{CONCLUSIONS}

The results of this initial pilot study suggest that while a majority of the psychiatrists in the sample were treating PTSD patients at time of survey, they remained quite conservative in regard to using MM to alleviate patients' PTSD symptoms. This is evidenced by that fact that only one (1.2\%) of the 83 respondents stated they had actually recommended the use of MM for the PTSD treatment in the past. Also, a large majority of psychiatrist respondents stated that they would not prescribe MM even if it were to be taken off the FDA's list of controlled substances. The authors' hypotheses that both younger respondents and those more familiar with established guidelines for MM use would be more supportive of MM use were not generally supported by results.

These results also demonstrate that few psychiatrists may be getting exposed to recommendations in the professional literature or conferences regarding MM and/or its derivatives as a treatment modality for PTSD. Only 11 (13.3\%) of the total sample reported that they had Sometimes or Often been exposed to such recommendations. This is in line with responses made related to the actual perceived scientific evidence for the use of MM for PTSD, in which a majority of the respondents indicated Unsure/There is Not Enough Research. Even though the authors' final MLR stepwise model showed three statistically significant model terms related to respondents' categorical opinions in the area, it is difficult to draw definitive conclusions from these study findings.

Perhaps the most revealing study finding came from the comments section in which respondents were allowed to provide open-ended statements concerning this practice issue. Many of these qualitative responses expressed ardent positions against the future use of MM for PTSD symptoms, but also against marijuana in general. As one psychiatrist stated, I have seen enough functional deficits from marijuana in patients across all age spectrums as well as cognitive decline. I would never prescribe medical marijuana for any reason. Many other respondents pointed out the negative effects of medical marijuana as a barrier to its therapeutic use.

Another respondent also questioned the validity of legislative processes for MM approval, stating, Medical marijuana is a lie. It was passed in several states by vote or legislative [action] rather than scientific rigor like other medicines. There are many cannabinoids and some may be useful but we need more studies.

In fact, the call for more research and literature on $\mathrm{MM}$ was a common theme amongst respondent comments. For example, one respondent stated, Thank you for including me in this survey. Some of your questions are quite provocative and will cause me to pursue additional reading in this area. It would be helpful if you provided your respondents a few relevant citations on the subject.

Future studies in this area would benefit from the use of psychometrically-tested surveys lending themselves to

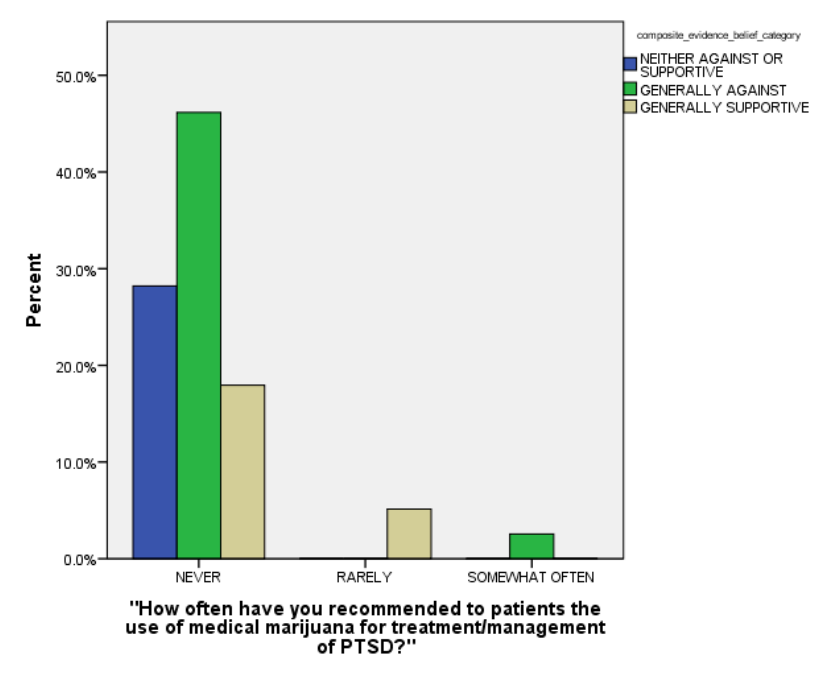

Figure 2: Composite Opinion Categories regarding the Use of Medical Marijuana for Post-Traumatic Stress Disorder $(\mathbf{n}=39)$

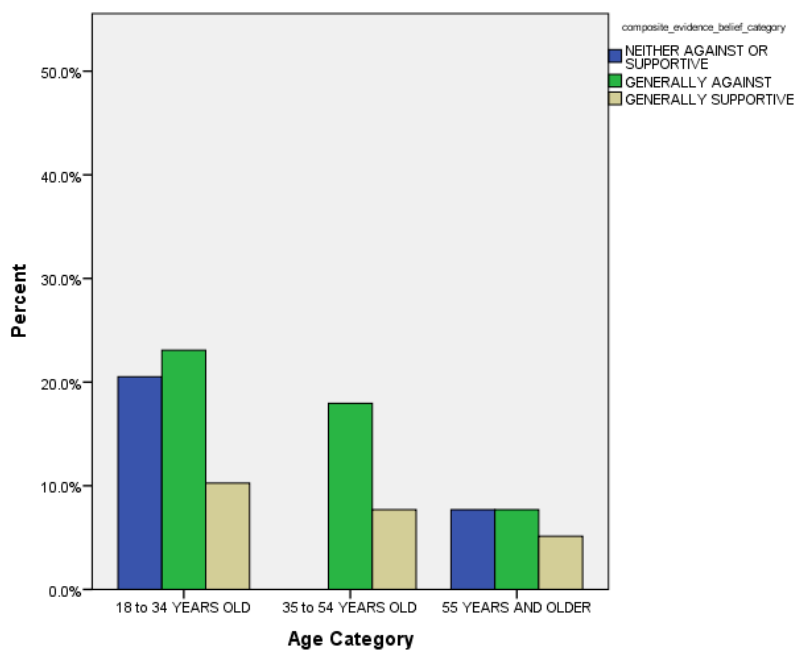

Figure 3: Composite Belief Category for use of Medical Marijuana for Post-Traumatic Stress Disorder by Age Category $(n=39)$

more detailed statistical analyses. It should be clearly acknowledged that this project team was very likely underpowered to detect meaningful sample subgroup differences that might be otherwise identified within larger future samples. Since marijuana is still illegal under federal law, doctors may not technically prescribe MM without violating the law, even in states where MM agents have been approved. Therefore, it is not unreasonable to conclude this fact could have influenced the responses from this study sample.

However, this cross-sectional survey study is still apparently one of the first to systematically examine the opinions of psychiatrists on the use of MM for the treatment of PTSD. Judging from these results, this remains an especially complex clinical care issue, with therapeutic, social, and legal facets that have not yet been thoroughly considered by practicing psychiatrists. As such, there is still a vital need 
for more studies to further clarify clinician opinions concerning the potential use of MM and marijuana-based medications for this disorder.

There remains a paucity of results from randomized controlled studies that could be used to inform current clinical guidance in the use of MM for PTSD. Ideally, the results from future research can inform the development of more evidenced-based guidelines for practicing psychiatrists. ${ }^{6,8,9}$

\section{FUNDING}

The authors report no external funding source for this study.

\section{CONFLICT OF INTEREST}

The authors declare no conflict of interest.

Submitted: September 15, 2016 EST, Accepted: December 15, 2016 EST

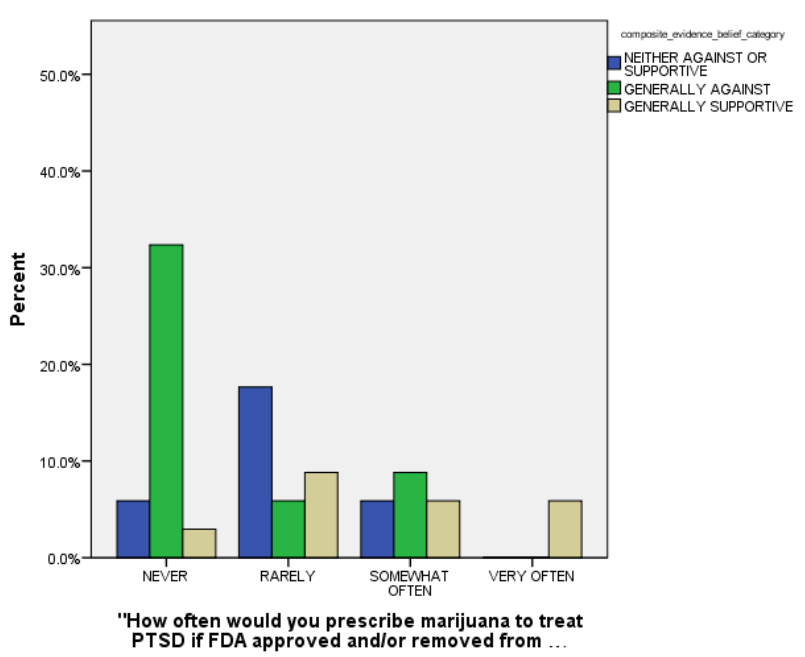

Figure 4: Composite Belief Categories by Likelihood of Future Prescription of Medical Marijuana for Post-Traumatic Stress Disorder (if ever FDA Approved) (n = 39)

This is an open-access article distributed under the terms of the Creative Commons Attribution 4.0 International License (CCBY-4.0). View this license's legal deed at http://creativecommons.org/licenses/by/4.0 and legal code at http://creativecommons.org/licenses/by/4.0/legalcode for more information. 


\section{REFERENCES}

1. Yehuda R. Post-traumatic stress disorder. N Engl J Med. 2002;346:108-114.

2. Kessler RC, Chiu WT, Demler O, Walters EE. Prevalence, severity, and comorbidity of twelvemonth DSM-IV disorders in the National Comorbidity Survey Replication (NCS-R). Arch Gen Psych. 2005;62(6):617-627.

3. Santiago PN, Ursano RJ, Gray CL, Pynoos RS, Spiegel D, Lewis-Fernandez R, et al. A Systematic Review of PTSD Prevalence and Trajectories in DSM-5 Defined Trauma Exposed Populations: Intentional and Non-Intentional Traumatic Events. PLOS ONE. 2013;8(4):e59236.

4. Blanco C, Hasin DS, Wall MM, Florez-Salamanca L, Hoertel N, Wang S. Cannabis Use and Risk of Psychiatric Disorders: Prospective Evidence From a US National Longitudinal Study. JAMA Psych. 2016;73(4):388-395

5. Controlled Substances Act of 1970. https://en.wikip edia.org/wiki/Controlled_Substances_Act. Accessed December 19, 2016.

6. Medical Marijuana Pros and Cons. 23 legal medical marijuana states and DC: laws, fees, and possession limits. http://medicalmarijuana.procon.org. Published 2016. Accessed December 19, 2016.

7. Michigan medical marijuana law expanding to include post-traumatic stress disorder. http://www.ml ive.com/lansing-news/index.ssf/2014/03/michigan_m edical marijuana law.html. Published 2014. Accessed December 19, 2016.

8. Benedek DM, Friedman MJ, Zatzick D, Ursano RJ. Guideline Watch (March 2009): Practice Guideline for the Treatment of Patients with Acute Stress Disorder and Posttraumatic Stress Disorder. American Psychiatric Association. http://psychiatryonline.org/p b/assets/raw/sitewide/practice_guidelines/guidelines/ acutestressdisorderptsd-watch.pdf. Accessed December 19, 2016.

9. Cougle JR, Bonn-Miller MO, Vujanovic AA Zvolensky MJ, Hawkins KA. Posttraumatic Stress Disorder and Cannabis Use in a Nationally Representative Sample. Psychol Addict Behav. $2011 ; 25(3): 554-558$.

10. Bonn-Miller MO, Babson KA, Vandrey R. Using cannabis to help you sleep: Heightened frequency of medical cannabis use among those with PTSD. Drug Alcohol Depend. 2014;136:162-165.
11. Betthauser K, Pilz J, Vollmer LE. Use and effects of cannabinoids in military veterans with posttraumatic stress disorder. Am J Health-Syst Pharm.

2015;72:1279-1284.

12. Yarnall S. The Use of Medicinal Marijuana for Posttraumatic Stress Disorder: A Review of the Current Literature. Prim Care Compan CNS Disord. 2015;17(3). doi:10.4088/PCC.15r01786

13. Papini S, Sullivan GM, Hien DA, Shvil E, Neria Y. Toward a translational approach to targeting the endocannabinoid system in posttraumatic stress disorder: A critical review of preclinical research. Biol Psych. 2015;104:8-18.

14. Fraser GA. The Use of a Synthetic Cannabinoid in the Management of Treatment-Resistant Nightmares in Posttraumatic Stress Disorder (PTSD). CNS Neurosci Therap. 2009;15:84-88.

15. Pietrzak RH, Huang Y, Corsi-Travali S, Zheng MQ, Lin S, Henry S. Cannabinoid Type I Receptor Availability in the Amygdala Mediates Threat Processing in Trauma Survivors. Neuropsychopharm. 2014;39:2519-2528.

16. Neumeister A, Normandin MD, Pietrzak RH, Piomelli D, Zheng MQ, Gujarro-Anton A. Elevated brain cannabinoid CB1 receptor availability in posttraumatic stress disorder: a positron emission tomography study. Molec Psych. 2013;18:1034-1040.

17. Charuvastra A, Friedmann PD, Stein MD. Physician Attitudes Regarding the Prescription of Medical Marijuana. J Addict Dis. 2005;24(3):87-93.

18. American Academy of Neurology. Medical Marijuana in Certain Neurological Disorders. http s://www.aan.com/Guidelines/home/GetGuidelineCont ent/650. Published 2014. Accessed December 19, 2016 .

19. Federation of State Medical Boards. Model Guidelines for the Recommendation of Marijuana in Patient Care. https://www.fsmb.org/Media/Default/P DF/BRD RPT 16-2 Marijuana Model Guidelines.pdf. Published 2016. Accessed December 19, 2016.

20. SurveyMonkey, Inc., Palo Alto, CA, USA. https://w ww.surveymonkey.com/.

21. IBM Corp. IBM SPSS Statistics for Windows, Version 22.0. 2013. 
22. Vittinghoff E, Shiboski SC, Glidden DV, McCulloch CE. Regression Methods in Biostatistics: Linear, Logistic, Survival, and Repeated Measures Models. New York: Springer Science+Business Media, Inc; 2005.
23. Yanchus NJ, Periard D, Osatuke K. Further examination of predictors of turnover intention among mental health professionals. J Psych Mental Health Nurs. 2016. 